九州大学学術情報リポジトリ

Kyushu University Institutional Repository

\title{
Fluorescence Enhancement of Samarium Picrate Tetraethylene Glycol Micro-sized Complex Doped in Poly (methyl methacrylate)
}

Kusrini, Eny

Department of Chemical Engineering, Faculty of Engineering, Universitas Indonesia

Virleenda. M. Setianingrum

Department of Chemical Engineering, Faculty of Engineering, Universitas Indonesia

Nur Alfin Hidayati

Department of Chemical Engineering, Faculty of Engineering, Universitas Indonesia

Mamat, Mazidah

Faculty of Science and Marine Environment, Universiti Malaysia

他

https://doi.org/10.5109/4055235

出版情報：Evergreen. 7 (2)，pp.292-296，2020-06. 九州大学グリーンテクノロジー研究教育センター バージョン：

権利関係 : 


\title{
Fluorescence Enhancement of Samarium Picrate Tetraethylene Glycol Micro-sized Complex Doped in Poly (methyl methacrylate)
}

\author{
Eny Kusrini $^{1 *}$, Virleenda. M. Setianingrum ${ }^{1}$, Nur Alfin Hidayati ${ }^{1}$, Mazidah Mamat ${ }^{2}$, \\ Yoki Yulizar ${ }^{3}$, Anwar Usman ${ }^{4}$ \\ ${ }^{1}$ Department of Chemical Engineering, Faculty of Engineering, Universitas Indonesia, Kampus Baru UI-Depok, \\ 16424, Indonesia \\ ${ }^{2}$ Faculty of Science and Marine Environment, Universiti Malaysia Terengganu, 21030 Kuala Nerus, Terengganu, \\ Malaysia \\ ${ }^{3}$ Department of Chemistry, Faculty of Chemistry, Universitas Indonesia, 16424 Depok, Indonesia \\ ${ }^{4}$ Department of Chemistry, Faculty of Science, Universiti Brunei Darussalam, Jalan Tungku Link, Gadong BE1410, \\ Negara Brunei Darussalam
}

*Author to whom correspondence should be addressed:

E-mail: ekusrini@che.ui.ac.id

(Received November 7, 2019; Revised May 2, 2020; accepted May 21, 2020).

\begin{abstract}
Abstact: Micro-sized complex of $\left[\mathrm{Sm}(\mathrm{Pic})_{2}\left(\mathrm{H}_{2} \mathrm{O}\right)(\mathrm{EO} 4)\right](\mathrm{Pic}) \cdot \mathrm{H}_{2} \mathrm{O}$ (where $\mathrm{EO} 4=$ tetraethylene glycol, Pic $=$ picrate anion) and its micro-sized polymethyl methacrylate (PMMA) composite have been synthesized by one step (in-situ method) and three steps (reprecipitation-evaporation) methods. Fluorescence intensity of ion $\mathrm{Sm}^{3+}$ ion in the Sm-PicEO4/PMMA micro-sized composite is higher than that in the Sm-Pic-EO4 micro-sized complex. The composite is potential to be applied as a luminescent center in organic light emitting devices for bright-orange emission coming from $\mathrm{Sm}^{3+}$ ions. This micro-sized rare earth metal and its composite can be used for engineering application.
\end{abstract}

Keywords: composite, fluorescence property, microsized complex, poly(methyl methacrylate), samarium

\section{Introduction}

The hybrid materials based on the organic and inorganic components have been extensively investigated because of their potential mostly for optical applications ${ }^{1-}$ 2). Fluorescence properties of lanthanides can be increased by co-doping with polymer ${ }^{2}$, making the lanthanide complexes essentially potential for photonic and/or organic light emitting devices (OLED) applications.

Rare earth metal complex-doped polymers are important because they still have the properties of the lanthanide complex, while they have a mechanically flexible. The stable transparent lanthanide complex-doped polymers can be formed from solution by mixing lanthanide complex with polymer matrix by spin-coating into uniform thin films.

Although samarium ion, $\mathrm{Sm}^{3+}$, generally has a low fluorescence ${ }^{3-5)}$, it is an interesting lanthanide emitter because of its bright-orange color. Therefore, $\mathrm{Sm}^{3+}$ complexes and their composites have been investigated for applications in optical, lighting, fiber optic, and gas sensor ${ }^{6-15)}$. The $\mathrm{Sm}^{3+}$ complexes display very large Stokes shift between the maxima of its absorption and emission spectrum and narrow bandwidth of emitted light ${ }^{12)}$. This character make it an excellent candidate for application in fluorescent probes in polymer industry ${ }^{12)}$.

The synthesis of $\left[\mathrm{Sm}(\mathrm{Pic})_{2}\left(\mathrm{H}_{2} \mathrm{O}\right)(\mathrm{EO} 4)\right](\mathrm{Pic}) \cdot \mathrm{H}_{2} \mathrm{O}$ complex (where EO4 = tetraethylene glycol, Pic = picrate anion) and its application as a luminescent center in OLED for bright emission have been explored 16). On the other hand, micro-sized europium-picrate-triethylene glycol (Eu-EO3-Pic) complex was doped with poly(methyl methacrylate), PMMA, has also investigated ${ }^{17)}$. These micro-sized rare earth metal complexes were synthesized by reprecipitation-evaporation method. The method is not only suitable for the synthesis of rare earth metal complexes, but it has also been recommended for preparation of micro- and nano-sized particles. 
The reported results indicated that the PMMA can be used to enhance the fluorescence intensity of the composites of lanthanide complexes ${ }^{17}$. Thus, mixing the polymers with lanthanides in the formation of materials or composite can enhance the optical properties ${ }^{18)}$. The role of the PMMA polymer in composites is to enhance the luminescence via preventing quenching process ${ }^{11,13,17-}$ 19). PMMA also can increase the electrical conductivity, photoconductivity, photo-induced charge transfer, photoluminescent, mechanical and magnetic properties of the composites ${ }^{20)}$. Organic-inorganic hybrid luminescent materials based on rare earth metal organic complexes has also reported by Feng and Zhang ${ }^{21)}$. The other polymer such as poly(p-phenylene vinylene was reported for carrier density and mobility in n-doped poly(p-phenylene vinylene) ${ }^{22)}$. On the other hand, the Si and $\mathrm{Cr}$ doping effects on growth and mechanical properties of ultrananocrystalline diamond/amorphous carbon composite films deposited on cemented carbide substrates by coaxial arc plasma deposition has also reported by Egiza and coworkers ${ }^{23)}$.

In this study, micro-sized [Sm(Pic $\left.)_{2}\left(\mathrm{H}_{2} \mathrm{O}\right)(\mathrm{EO} 4)\right](\mathrm{Pic}) \cdot \mathrm{H}_{2} \mathrm{O}$ complex and its PMMA composite were synthesized by one step (insitu) and three steps (reprecipitation-evaporation) methods. The micro-sized complex and composite were characterized in details, including their fluorescence properties. The sharp and intense orange luminescence from this micro-sized complex and its composite are anticipated to be the emitter suitable for orange OLED. In addition, aluminum (Al) foil was used as substrate as it is a better source of $\mathrm{Al}^{3+}$ ions for complexation with monoprotic bidentate chelating ligand, which can form complex with many metal ions ${ }^{24,25)}$.

\section{Experimental}

\subsection{Materials}

Tetraethylene glycol $\left[\mathrm{C}_{8} \mathrm{H}_{18} \mathrm{O}_{5}, 99.5 \%\right]$ and PMMA with MW = 120000 were purchased from Across (New Jersey, USA). Picric acid [ $\left(\mathrm{NO}_{2}\right)_{3} \mathrm{C}_{6} \mathrm{H}_{2} \mathrm{OH}, 98 \%$ ] was purchased from BDH (Poole, England). [ $\mathrm{Sm}\left(\mathrm{NO}_{3}\right)_{3}$. $6 \mathrm{H}_{2} \mathrm{O}$ ] salt with a grade of $99.9 \%$ was purchased from Johnson Matthay Electronics (Milwaukee, USA). Other chemicals and solvent were at least of analytical grade and were used without further purification.

\subsection{Preparation of the bulk}

\section{[Sm(Pic) $\left.{ }_{2}\left(\mathrm{H}_{2} \mathrm{O}\right)(\mathrm{EO} 4)\right](\mathrm{Pic}) . \mathrm{H}_{2} \mathrm{O}$ complex}

The preparation bulk Sm complex was the same as that in the analogous $\mathrm{Sm}$ complex ${ }^{11)}$. All starting materials, i.e. EO4 (0.78 g, $4 \mathrm{mmol})$, HPic (0.91 g, 4 mmol), $\mathrm{Sm}\left(\mathrm{NO}_{3}\right)_{3} .6 \mathrm{H}_{2} \mathrm{O}(0.434 \mathrm{~g}, 1 \mathrm{mmol})$ were mixed together into $50 \mathrm{~mL}$ beaker containing $15 \mathrm{~mL}$ of acetonitrile:methanol (1:1v/v). To allow a slow evaporation of solution at room temperature, a beaker was covered by aluminum foil with small hole in aluminum. The bulk Sm complex was isolated after three days under room temperature. This complex was named as bulk Sm complex which was further used for preparation of microsized Sm complex.

\subsection{Preparation of the micro-sized Sm complex}

The micro-sized Sm complex was prepared by mixing crystalline solids of bulk Sm complex (0.02 g) and $1 \mathrm{~mL}$ aquabidest at $40^{\circ} \mathrm{C}$ in a reaction tube. The solution was cooled at room temperature. A clear yellow solution was dispersed in chloroform with a ratio of complex 1:2, the solution was dispersed onto glass slides. After that, the glass slide was dried in desiccator. Upon complete drying, micro-sized Sm complex was obtained for further characterization.

\subsection{Preparation of micro-sized Sm/PMMA composite}

\section{using one step (in situ) method}

All of the $\mathrm{Sm}\left(\mathrm{NO}_{3}\right)_{3} .6 \mathrm{H}_{2} \mathrm{O}$ salt $(0.01 \mathrm{~g})$, picric acid (0.02 g) and EO4 (0.02 g), PMMA (0.95 g) were mixed and under stirring into $10 \mathrm{~mL}$ acetone in a beaker. The Sm/PMMA composite solution was coated on $\mathrm{Al}$ substrate using a speed of $100 \mathrm{rpm}$ for $2 \mathrm{~min}$. The microsized composite using one step Sm/PMMA was obtained and further characterization.

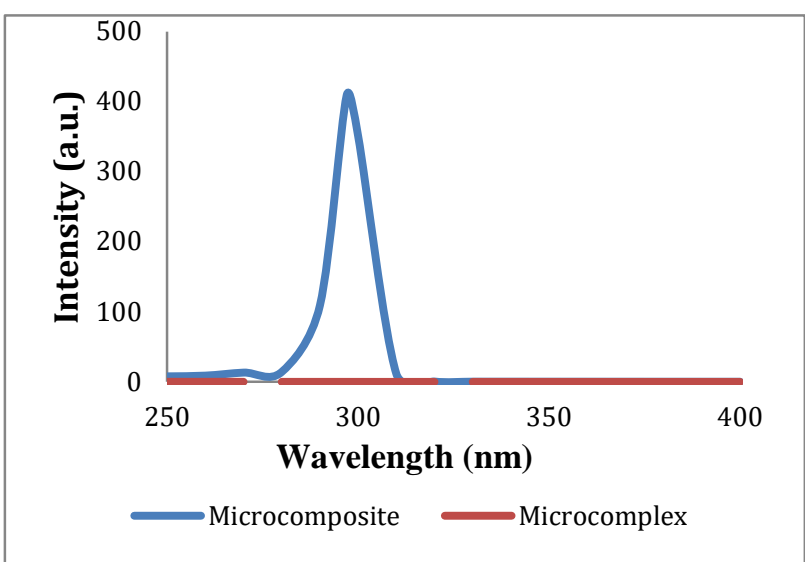

Fig. 1. Comparison the excitation properties of micro-sized Sm complex and its composite that prepared by three steps with emission wavelength of $594 \mathrm{~nm}$

\subsection{Preparation of micro-sized Sm/PMMA composite}

\section{using three steps method}

The micro-sized Sm/PMMA composite was prepared using three steps according the method previously reported ${ }^{12)}$. The composite was prepared by mixing all of the micro-sized Sm complex (0.0025 g), PMMA (0.98 g) with ratio of 1: 392 in $10 \mathrm{~mL}$ acetone in a reaction tube. The solution was coated onto Aluminum (Al) substrate with a speed of $100 \mathrm{rpm}$ using spin coating method. This composite was named as micro-sized Sm/PMMA 
composite.

\subsection{Physical measurements}

Fluorescence properties of samples were analyzed using Fluorescence Spectrophotometer (Type F 2000, Hitachi) at room temperature with a xenon light source, and the excitation and emission slits used were both $10 \mathrm{~nm}$. The compounds of Sm (0.01 g) was dissolved in acetonitrile $(5 \mathrm{~mL})$. The emission spectrum of the solution was scanned from 220 to $800 \mathrm{~nm}$ at $240 \mathrm{~nm} / \mathrm{min}$. Particle size of samples were determined using Malvern Instruments, Zetasizer Nano Series, nano S (Red Badge) Model ZEN1600. The compound (0.0065 g) was dissolved in $5 \mathrm{~mL}$ double distilled water. The spectrum size distribution was scanned from 10 to $10,000 \mathrm{~nm}$.

\section{Results and Discussion}

\subsection{Fluorescence Characterization}

Fluorescence properties of micro-sized Sm complex and its micro-sized Sm/PMMA composite that prepared by three steps at excitation wavelength of $295 \mathrm{~nm}$ is shown in Figure 1. This excitation wavelength was selected to obtain the highest intensity of emission property ${ }^{21)}$. The excitation spectrum of the micro-sized Sm complex and its composite display a broad band (280 $-310 \mathrm{~nm}$ ) with maxima at 292 and $297 \mathrm{~nm}$, respectively, which corresponds to the excitation of the EO4 ligand ${ }^{15)}$.

The emission spectrum of micro-sized Sm/PMMA composite show a broad peak $(560-630 \mathrm{~nm})$ with maxima at $594 \mathrm{~nm}$, while for micro-sized Sm complex displays a peak (590 - $600 \mathrm{~nm})$ with maxima at 594 $\mathrm{nm}$. This typical spectral features of the micro-sized Sm complex and its composite that prepared by three steps is assigned with hypersensitive emission peak at $594 \mathrm{~nm}$. This peak is assigned for ${ }^{4} \mathrm{G}_{5 / 2}-{ }^{6} \mathrm{H}_{7 / 2}$ transition and it is also related to the characteristic emission of the $\mathrm{Sm}^{3+}$ ions ${ }^{15}$ ) (see Fig. 2). The intensity of the hypersensitive ${ }^{4} \mathrm{G}_{5 / 2}-{ }^{6} \mathrm{H}_{7 / 2}$ transition is higher in the micro-sized composite. The magnetic dipole transition of the micro-sized Sm/PMMA composite exhibits obtrusive peak at $594 \mathrm{~nm}$, whereas this transition is very weak in the micro-sized Sm complex.

Fig. 2. Comparison the emission properties of micro-sized Sm complex and its composite that prepared by three steps with excitation wavelength of $295 \mathrm{~nm}$

Figs. 3 and 4 showed the comparison of excitation and emission spectra of micro-sized Sm/PMMA complex composite that synthesized using one step and three steps methods, respectively. The intensity of microsized complex composite that prepared using one and three steps are significantly different. The synthesizing and mixing technology for preparation of micro-sized Sm complex composite has successfully. By doping with PMMA, the emission intensity of micro-sized composite increased more than six thousand folds (see Fig. 2). In this

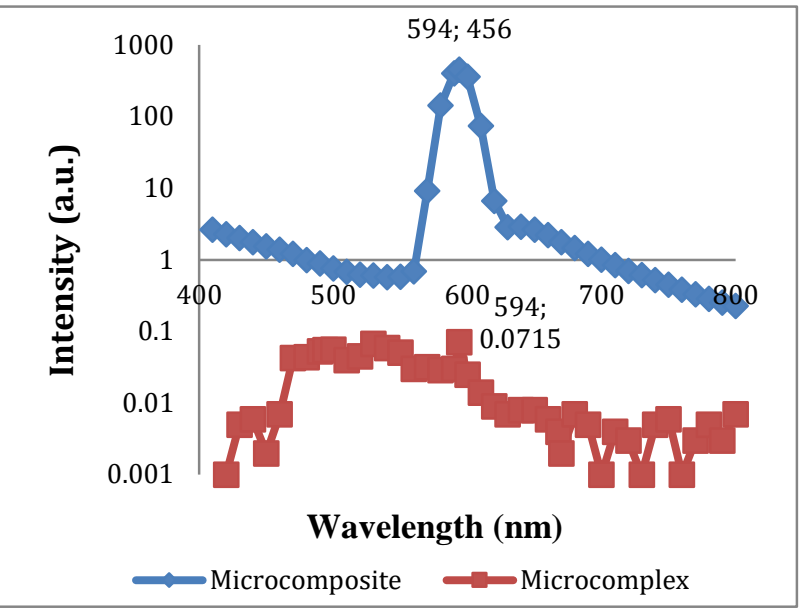

study, by using a polymer and small size of complex by dispersing in the micro-sized Sm complex as an emitter layer into a host material (PMMA) can prevent the luminescence quenching.

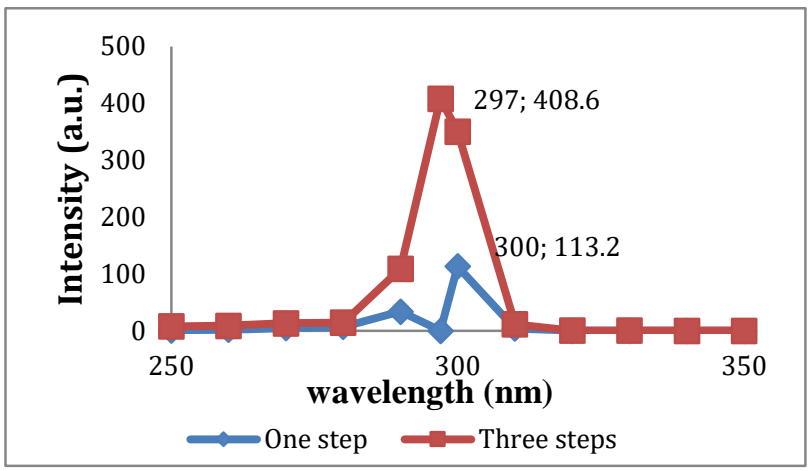

Fig 3. Comparison the excitation properties of Sm/PMMA micro-sized complex composite with emission wavelength of $594 \mathrm{~nm}$

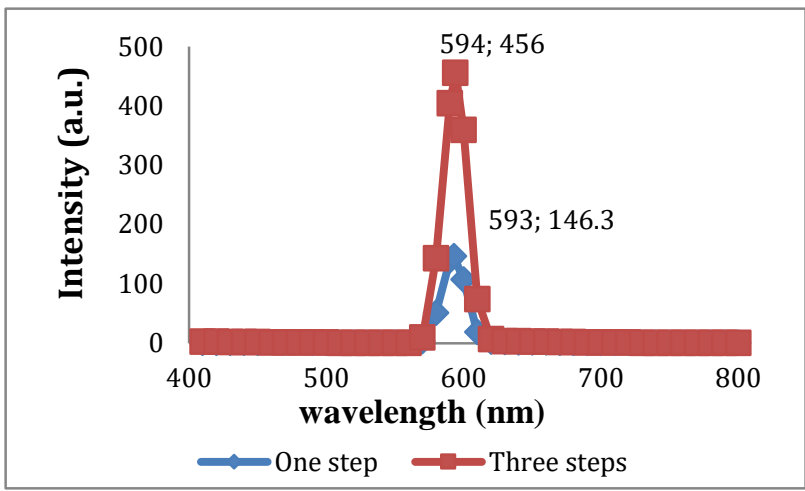

Fig. 4. Comparison the emission properties of micro-sized Sm/PMMA complex composite that synthesized using one step and three steps methods with excitation wavelength of $295 \mathrm{~nm}$

\subsection{Particle size distribution studies}

In this study, the colloidal of Sm complex was prepared in a solution with water suspension. The particle size distribution of micro-sized [ $\left.\mathrm{Sm}(\mathrm{Pic})_{2}\left(\mathrm{H}_{2} \mathrm{O}\right)(\mathrm{EO} 4)\right](\mathrm{Pic})$. 
$\mathrm{H}_{2} \mathrm{O}$ complex, Sm/PMMA composite by three steps and micro-sized Sm/PMMA composite by in-situ method were 525.4, 623.6 and $831.4 \mathrm{~nm}$, respectively (see Figs. 5 - 7). Particle size distribution of micro-sized Sm/PMMA composite using three steps is higher than those found for the micro-sized composite using in-situ method because of the agglomeration of bulk Sm complex in composite form. Even though, it is noted that preparation of microsized composite by one step (in-situ method) and three steps (reprecipitation-evaporation method) have successfully synthesized. However, the emission intensity and particle size distribution of them are different. Increasing the particle size distribution of micro-sized Sm complex after doped with PMMA because the concentration of PMMA in Al substrate was dominant than those found in the micro-sized Sm complex. The combination of micro-sized Sm/PMMA composite and its $\mathrm{Al}$ substrate is covalently bonded and resulted in the production of micro-sized composite with flourescent properties in the orange regions and suitable for emission of $\mathrm{Sm}^{3+}$ ions. These micro-sized rare earth metal and their composites can be used as an active component for engineering application. Low cost adsorbent can be produced from this composite and used for removal of dyes, toxic anions and heavy metals in wastewater. The use of these composites for separation of toxic elements from waste water is very interesting to be developed because these rare earth metals that are capable of binding to anions such as sulfate and fluoride ions.

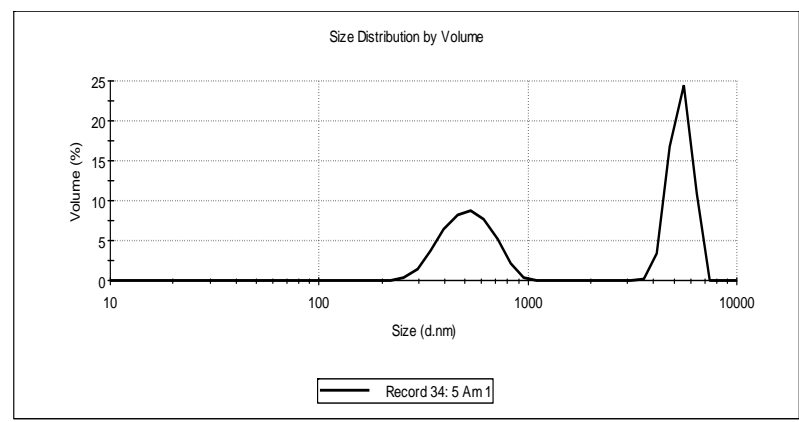

Fig. 5. The micro-sized Sm complex of with particle size distribution of $525.4 \mathrm{~nm}$

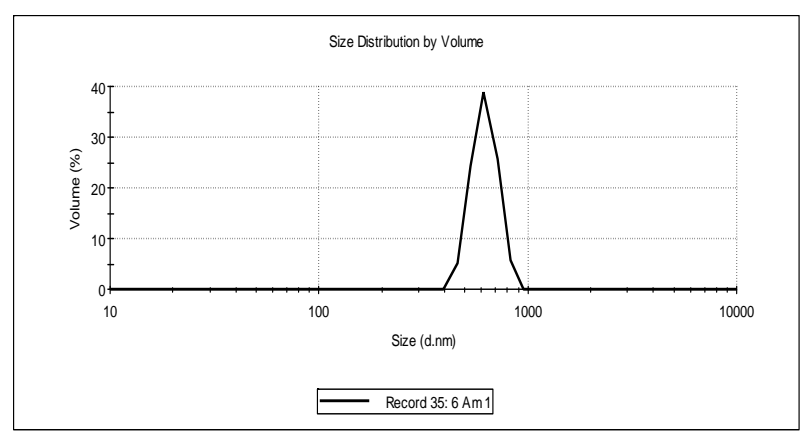

Fig. 6. The micro-sized Sm/PMMA composite of that prepared with three steps with particle size distribution of $623.6 \mathrm{~nm}$

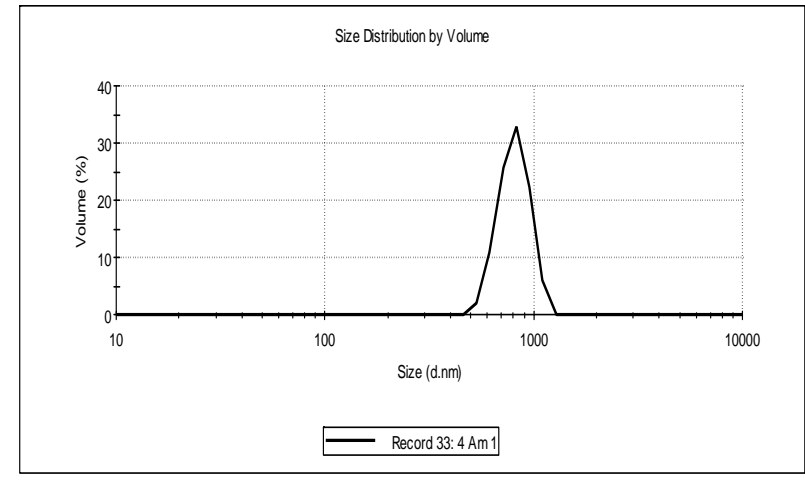

Fig. 7. The micro-sized Sm/PMMA composite of that prepared with single (one) step with particle size distribution of 831.4 $\mathrm{nm}$

\section{Conclusion}

The flourescence of the micro-sized complex of samarium ion as a function of its environment of polymer poly(methylmethacrylate), PMMA, and different substrates are important to evaluate the fluorescence character, energy transfer process and the effects of PMMA polymers and theirs thin film substrates. The micro-sized (Sm(Pic) $\left.)_{2}(\mathrm{EO} 4)\left(\mathrm{H}_{2} \mathrm{O}\right)_{2}\right](\mathrm{Pic})$ complex was prepared using one step (in-situ) and three steps (evaporation and re-precipitation) methods, then they were doped with PMMA, after that following to coated with Al substrate. The combination of Sm/PMMA micro-sized composite and its substrate is covalently bonded and resulted in the production of micro-sized composite with fluorescence spectra in the orange regions and suitable for emission of $\mathrm{Sm}^{3+}$ ions. These results showed the fluorescence intensity of ion $\mathrm{Sm}^{3+}$ ion in micro-sized composite is higher than only micro-sized complex. Finally, the micro-sized Sm complex and its composite can be used as a luminescent center in organic light emitting devices (OLED) for bright-orange emission coming from $\mathrm{Sm}^{3+}$ ions. Further research, these micro-sized rare earth metal and composites can be used as an active component for engineering application.

\section{Acknowledgments}

The authors greatly acknowledge the Universitas Indonesia for research grant award through PIT9 No. NKB-0055.UN2.R3.1/HKP.05.00/2019 for financial support.

\section{References}

1) A. N. Bugrov, R.Yu. Smyslov, T. D. Anan'eva, A.Y. Zavialov, D.A. Kirilenko, O.V. Almjashev, Journal of Luminescence 207, 157-168 (2019).

2) P. Miluski, M. Kochanowicz, J. Zmojda, T. Ragin, D. Dorosz, Optical Materials 87, 112-116 (2019).

3) P.C.R. Soares-Santos, F.A. Almeida Paz, R.A. Sa Ferreira, J. Klinowski, L.D. Carlos, T. 
Trindade, H.I.S. Nogueira, Polyhedron 25, 2471 (2006).

4) A.P. Bassett, S.W. Magennis, P.B. Glover, D.J. Lewis, N. Spencer, S. Parsons, R.M. Williams, L. De Cola, Z. Pikramenou, J. Am. Chem. Soc. 1269413 (2004).

5) S. Quici, M. Cavazzini, G. Marzanni, G. Accorsi, N. Armaroli, B. Ventura, F. Barigelletti, Inorg. Chem. 44, 529 (2005).

6) Z. Nie, H. Lee, H. Shin, H. Lee, K.-S. Lim, M. Lee, Spectrochimica Acta Part A: Molecular and Biomolecular Spectroscopy 72, 554-560 (2009).

7) A.K. Singh, S.K. Singh, R. Prakash, S.B. Rai, Chemical Physics Letters 485, 309-314 (2010).

8) L. Huang, K. Tsang, E.Yue-Bun Pun, S.Xu, Optics Communications 283, 1363-1365 (2010).

9) B. Renganathana, D. Sastikumar b, R. Srinivasanc, A.R. Ganesan, Materials Science and Engineering B 186, 122-127 (2014).

10) J. Liu, S. Liu, Y. Chen, Q. Zhao, Y. Zhao, W. Xiang, X. Liang, B. Ren, Ceramics International 45, 2268822693 (2019).

11) W. A. Dar, A.B. Ganaie, K. Iftikhar, Journal of Luminescence 202, 438-449 (2018).

12) M. Topa, J. Ortyl, A. Chachaj-Brekiesz, I. KamińskaBorek, M. Pilch, R. Popielarz, Spectrochimica Acta Part A: Molecular and Biomolecular Spectroscopy 199, 430-440 (2018).

13) M. Bortoluzzi, G. Paolucci, M. Gatto, S. Roppa, F. Enrichi, S. Ciorba, B. S. Richards, Journal of Luminescence 132, 2378-2384 (2012).

14) Z. Kin, H. Kajii, Y. Hasegawa, T. Kawai, Y. Ohmori, Thin Solid Films 516, 2735-2738 (2008).

15) R. B. Muterle, F. Fabri, R. Buffon, W. de Oliveira, U. Schuchardt, Applied Catalysis A: General 317, 149153 (2007).

16) E. Kusrini, M. I. Saleh, Y. Yulizar, N.K. Za’aba, W.H. Abd. Majid, Journal of Luminescence 131, 19591965 (2011).

17) E. Kusrini, D. Tristantini., Slamet, V.M. Setianingrum, Y. Yulizar, International Journal of Technology 5(1), 70-78 (2014).

18) S. Khursheed, P. Biswas, V. K. Singh, V. Kumar, H.C. Swart, J. Sharma, Vacuum 159, 414-422 (2019)

19) H. Jiu, L.Zhang, G. Liu, T. Fan, Journal of Luminescence 129 (2009) 317-319.

20) R. Chai, H. Lian, P. Yang, Y. Fan, Z. Hou, X. Kang, J. Lin, Journal of Colloid and Interface Science, 336, 46-50 (2009).

21) J. Feng, H. Zhang, Chemistry Social Review, 42, 387410 (2013).

22) S. Sakiyama, T. Komura, H. Iwashita, N. Mizutani, Ka. Fujita, EVERGREEN Joint Journal of Novel Carbon Resource Sciences \& Green Asia Strategy, 03, Issue 01, 18-20 (2016).

23) M. Egiza, H. Naragino, A.Tominaga, K.Murasawa, Hi. Gonda, M. Sakurai, T. Yoshitake, EVERGREEN
Joint Journal of Novel Carbon Resource Sciences \& Green Asia Strategy, 03, Issue 01, 32-36 (2016).

24) W. Kim, G. Lee, M. Kim, J. Park, S. Jo, D. Sung Yoon, Y.H. Park, J.Hong, J. Park, Sensors and Actuators B 255, 2179-2186 (2018).

25) C. Sun, J. Sun, F. Qiu, W. Li, Z. Chang, L. Zhang, Spectrochimica Acta Part A: Molecular and Biomolecular Spectroscopy 188, 1-7 (2018). 